\title{
EFFECT OF DIFFERENT STORAGE CONDITIONS ON SUGARCANE WEIGHT LOSS
}

\author{
Dr. Pooja Mehrotra \\ Engineering Science, G. H. Raisoni College of Engineering and Management Wagholi, Pune. \\ Dr. Nidhi Sharma \\ Engineering Science, JSPM's Jayawantrao Sawant College of Engineering Hadapsar, Pune
}

\begin{abstract}
Sugarcane is a perishable commodity and its processing into sugar must be done rapidly only after its harvesting to avoid sugar loss. The quality of harvested sugarcane has got significant importance due to the fact that the payments are made on the basis of estimated recoverable sugar in some countries, while in India sugarcane price is paid on weight basis. Therefore, in India it is quite obvious that the growers are more worried about cane weight than its quality while the factory owners on the other hand are worried about the sugarcane quality and hence on ultimate recoverable sugar. Author in present study has discussed the effect of different storage conditions on cane weight on cane variety $\operatorname{CoS} 94257$ and ways to minimize the weight loss in sugarcane.
\end{abstract}

Keywords- Post harvest deterioration, Weight loss\%, Storage Conditions etc.

\section{INTRODUCTION}

The sugar industry in India is the second largest agro based industry, next only to cotton industry. Weight of sugarcane is important from sugar factory point of view as it gives broad idea about the health of the cane to be crushed. However it is more so important from the farmer's point of view as in our country cane price is paid on weight basis. Since sugarcane contains $72-76 \%$ water by weight, any staling after harvesting of the sugarcane will lead to loss of weight due to escape of water from sugarcane stalk since phenomenon of evaporation is directly linked with the thermal energy, it is expected that weight loss shall be more when the ambient temperature is higher. As sugarcane price is paid on weight basis in India, prevention of weight loss in sugarcane is of prime importance from the economy of growers as well as sugar industry point of view. The most important and dominating factor in pulling down sugar cane weight as well as sugar recovery is the post-harvest deterioration of cane, which is caused due to time lag between harvesting and milling. The late crushing of sugarcane in the factories is assigned to labor scarcity, limited crushing capacity, inadequate transport facilities and absence of scientific harvesting schedule.

During staling, the major physical change is the loss in cane weight which is associated with sucrose loss and decrease in sugar recovery. The loss in cane weight is due to the evaporation of water content which is positively correlated with the loss of sucrose from cane through desperation and inversion. It is also observed that the rate at which sucrose disappears depends upon various external factors such as sun rays, rain and humidity of the atmosphere as such place and condition of sugarcane is of great importance.

The work carried out by Hall ${ }^{1}$ points towards the fact that the inversion is caused by one or more enzyme which are present to a small extent in freshly harvested cane and which becomes more active during staling. Young ${ }^{2}$ in Queensland, evaluated sugar and weight changes occurring in cut and standing burnt cane and reported that the deterioration was higher in burnt cut cane than in burnt standing cane. Studies by $\mathrm{Calma}^{3}$ in the Philippines also showed greater sugar loss for burnt standing cane than for cut cane. Samuels also observed the same results. Wood and Butoit ${ }^{4}$ were of the opinion that the cane starts deteriorating immediately on harvest and the rate of deterioration varies according to the weather conditions. Studies on cane deterioration by Irvin and Foster ${ }^{5}$ have carried good amount of research work on deterioration of cane during post harvest period.

Srivastava et al ${ }^{6}$ presented in his studies that in India, 


\section{International Journal of Engineering Applied Sciences and Technology, 2020 Vol. 5, Issue 5, ISSN No. 2455-2143, Pages 60-66 \\ Published Online September 2020 in IJEAST (http://www.ijeast.com)}

crushing season generally starts from November end and continues till April or May with different climatic conditions like minimum and maximum temperatures . Saxena ${ }^{7}$ et al also emphasized that postharvest sugar loss is a complicated problem for sugar industry and it should be treated very seriously . $\mathrm{Uppal}^{8}$ et al also carried out analysis on post harvest deterioration of cane. Verma ${ }^{9} \mathrm{et}$ al , Mahadevaiah and Dezfuly ${ }^{10}$ and Solomon et ${ }^{11}$ suggested during their investigation that sugarcane weight loss generally occurs due to evaporation loses and increased respiration. According to Amin ${ }^{12}$ et al the glucose ratio of cut cane increased drastically during storage under open conditions.

The present study was undertaken to access sugarcane weight loss under different storage conditions of sugarcane storage.

\section{MATERIAL AND METHODS}

During the experiment the sugarcane variety $\operatorname{CoS}$ 94257 was taken. In hot climatic conditions (i.e April) the crop was harvested ,topped and de trashed and then three cane bundles having 15 nos. were prepared. Out of three bundles, one was exposed to prevailing environmental conditions and was designated as controlled. Among the rest, one was sprayed with water once during the day and referred as water sprayed samples. The other was kept in shed, away from sun rays and was designated as stored samples. To access the loss in weight under different storage conditions cane bundles were weighed every day after $24 \mathrm{hrs}$ upto $96 \mathrm{hrs}$. The same procedure was adopted in cold climatic conditions (i.e. in January) to access the weight loss percent in sugarcane.

\section{RESULT \& DISCUSSION}

\section{Weight loss \%}

The average data of weight loss $\%$ of cane variety $\mathrm{CoS} 94257$ during summers and winters is given in Table 1 and 2 respectively. The graphical representation has been made in Fig. 1 \&2.
A review of Table 1 gives an idea about the loss in weight percent of sugarcane during summers. The data obtained during the experiment suggests that there was a rapid loss in weight percent of sugarcane only after 24 hours of storage, which was about $3.7 \%$ ,3.0\% and $2.6 \%$ respectively for control, stored and water sprayed samples. The loss in weight was quite rapid after every $24 \mathrm{hrs}$ upto 96hrs. After $72 \mathrm{hrs}$ the loss in weight was $9.0 \%, 6.8 \%$ and $5.7 \%$ respectively for controlled, stored and water sprayed samples. The overall loss during these experiments lasting $96 \mathrm{hrs}$ was $12.8 \%, 9.7 \%$ and $8.3 \%$ respectively.

The data presented in Table 2 indicates the loss in weight $\%$ of sugarcane during winters. The weight loss \% of sugarcane after $24 \mathrm{hrs}$ was found to be $2.6 \%, 2.2 \%$ and $2.0 \%$ respectively for controlled, stored and water sprayed samples which was much lower than that observed during summers further the loss in weight occurred at slow rate in first $48 \mathrm{hrs}$ but after $72 \mathrm{hrs}$ the trend becomes significant.

The comparative study of Table $1 \& 2$ reveals that the loss in cane weight was higher in summers than in winters due to high atmospheric temperature, which causes rapid loss of water from sugarcane. It can be observed from tables that after $96 \mathrm{hrs}$ of storage the loss in cane weight in summers was $12.8 \%, 9.7 \%$ and $8.3 \%$ for controlled, stored and water sprayed samples and during winters it was observed to be about $8.0 \%, 6.7 \%$ and $5.9 \%$ for controlled stored and water sprayed samples respectively.

Thus these results suggest that the loss in cane weight could be minimized upto some extent by spraying water on cane heaps or even by keeping them in shade.

The graphical representation made on these basis also demonstrate that the loss in cane weight was higher in summers and the most effective treatment to avoid loss in cane weight was water spraying on cane heaps. 
International Journal of Engineering Applied Sciences and Technology, 2020

Vol. 5, Issue 5, ISSN No. 2455-2143, Pages 60-66

Published Online September 2020 in IJEAST (http://www.ijeast.com)

TABLE No. :1 Average Weight Loss\% of Sugarcane under different storage conditions during Winters

\begin{tabular}{|c|c|c|c|}
\hline DURATION/PARTICULARS & CONTROLED & STORED & WATER \\
\hline $00 \mathrm{hrs}$ & - & - & - \\
\hline $24 \mathrm{hrs}$ & 3.7 & 3.0 & 2.6 \\
\hline $48 \mathrm{hrs}$ & 6.1 & 4.8 & 4.1 \\
\hline $72 \mathrm{hrs}$ & 9 & 6.8 & 5.7 \\
\hline $96 \mathrm{hrs}$ & 12.8 & 9.7 & 8.3 \\
\hline
\end{tabular}

TABLE No. :2 Average Weight Loss\% of Sugarcane under different storage conditions during Winters

\begin{tabular}{|c|c|c|c|}
\hline DURATION/PARTICULARS & CONTROLED & STORED & $\begin{array}{c}\text { WATER } \\
\text { SPRAYED }\end{array}$ \\
\hline $00 \mathrm{hrs}$ & - & - & - \\
\hline $24 \mathrm{hrs}$ & 2.6 & 2.2 & 2.0 \\
\hline $48 \mathrm{hrs}$ & 3.8 & 3.2 & 2.8 \\
\hline $72 \mathrm{hrs}$ & 5.7 & 4.8 & 4.2 \\
\hline $96 \mathrm{hrs}$ & 8.0 & 6.7 & 5.9 \\
\hline
\end{tabular}

FIGURE NO.:1 Average Weight Loss \% of Sugarcane under different storage conditions during Summers

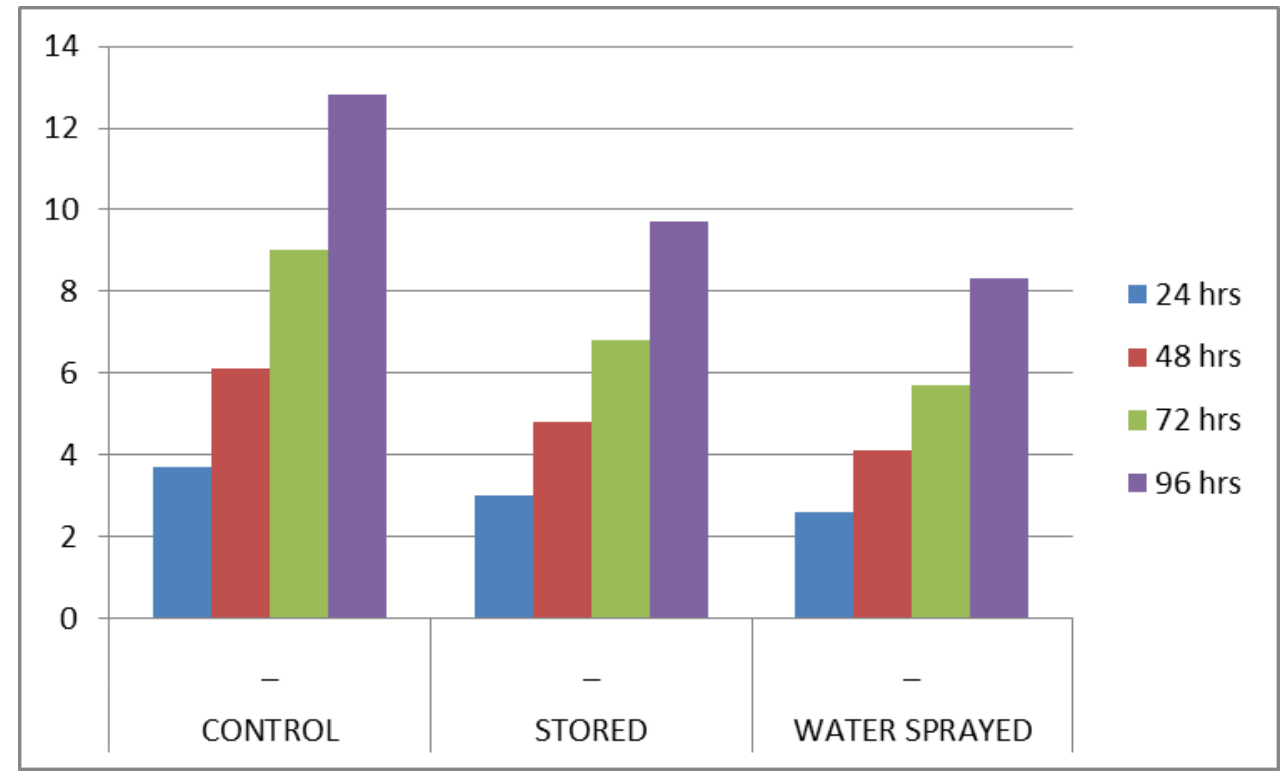


FIGUR NO.:2 Average Weight Loss\% of Sugarcane under different storage conditions during Winters

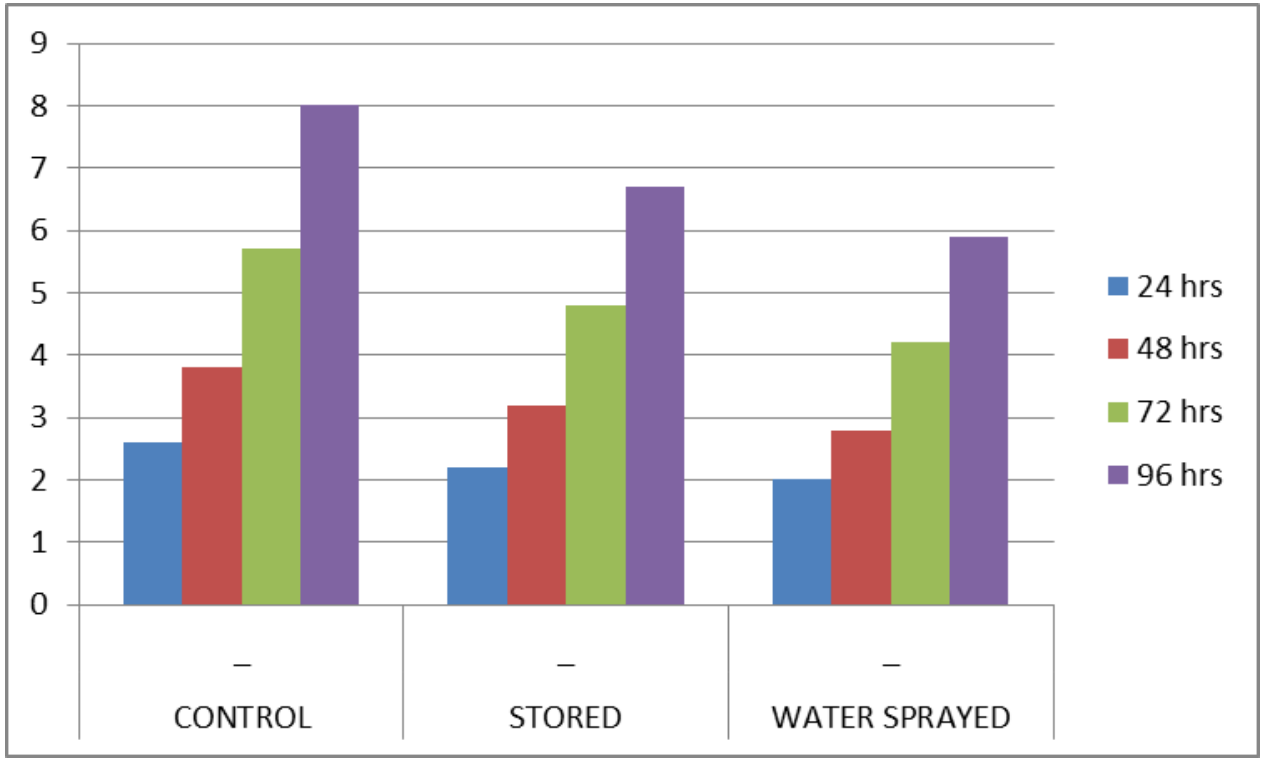

\section{CONCLUSION}

One aspect which is not closely associated with the quality parameters but worries both factories and farmers, is the loss in weight of cane after harvest. Since in our country price of sugarcane is paid weight basis, it affects the farmers more. Since weight loss is caused due to escape of moisture from the cane stalks apart from various external factors like temperature and humidity, it is the place and method of sugarcane storage which determines the rate of escape of moisture and hence the weight loss. Studies were thus conducted to ascertain loss in cane weight under various climatic conditions and places, method of storage. It was observed that the cane incurs max. weight loss in hot climatic conditions that too when kept in open conditions then the cane kept in shed or to one over which water had been sprayed. For $96 \%$ of exposure, loss in weight loss was estimated to be $12.8 \%, 9.7 \%$ and $8.3 \%$ in summers and $8.0 \%, 6.7 \%$ and $5.9 \%$ in winters for controlled, stored and water sprayed samples respectively. Therefore spraying with water once during the day on cane bundles was found to be most effective as the weight loss in this cane bundle was less to that for the controlled cane samples.

\section{REFERENCES}

[1]. Hall JA (1914) Rate of inversion in cut cane. Int Sugar J 16: 235

[2]. Young HE (1963) The deterioration of burnt standing cane and burnt cut cane.Proc.Int. Soc. Sugar Cane Technol. 11: 307-311.

[3]. Tilbury RH (1969) The ecology of Leuconostoc mesenteroides and control of post harvest bio deterioration of sugarcane

[4].

M.J. Robertson, R.C. Muchow, R.A. Donaldson, N.G. Inman-Bamber, A.W. WoodEstimating the risk associated with drying-off strategies for irrigated sugarcane before harvest

[5]. D.R. Parashar Behaviour of drought affected cane during the process of sugar manufacture Indian Sugar, 10 (1) (1960), pp. 5558

[6 ] Shrivastava ,A.K., Misra, V., Srivastava, T.K., Singh, V.K., Shukla, S.P. 2015. Climate change Induced Multiple Abiotic Stress Affecting Sugarcane and Their Mitigation. Souv. of 26th Meeting of Sugarcane Res \& Devel workers of AP 57-63.

[7]. S. Solomon Post-harvest cane deterioration and its milling consequencesSugar Tech, 2 (2000), p. 1

[8]. S.K. Uppal Post harvest losses in sugarcaneSugar Tech, 5 (2003), pp. 93-94 
[9].T. Krishnakumar, C. Thamilselvi, C.T. Deva dasEffect of delayed extraction and storage on quality of sugarcane juice Afr. J. Agri. Res., 8 (10) (2013), pp. 930-935

[10]. S. SolomonPost-harvest cane deterioration and its milling consequencesSugar Tech, 2 (2000), p. 1
[11].V. Misra, S. Solomon, A.K. Shrivastava, S. P. Shukla, M.I. AnsariPost-harvest sugarcane deterioration: Leuconostoc and its effect J. Funct. and Environ Bot., 6 (1) (2016), pp. 1-7 